\title{
PRODUCTIVITY IMPROVEMENT AT ASSEMBLY STATION USING WORK STUDY TECHNIQUES
}

\author{
Ravikumar Kamble ${ }^{1}$, Vinayak Kulkarni ${ }^{2}$ \\ $M$ Tech in Production management in BVBCET HUBLI KARNATAKA INDIA \\ Assistant Professor Industrial Production \& Engg BVBCET HUBLI KARNATAKA INDIA
}

Abstract

This is intended to study the cycle time and existing method of different work stations and suggesting improved method for the same so as to reduce the cycle time and to improve productivity. During the plant visit and discussions made with the proprietor it was found that the inefficient time associated with the assembly area is more. Hence the assembly section was selected for work study. The importance of thist work is directly related to the reduction of the inefficient time and increasing the productivity. The new approach of studying the operations by Video work study techniques is the first of its kind in Hubli. The advantages of this project lies in the improvement of the productivity by reducing the cycle time, smooth flow of components for assembly, reducing the worker fatigue, suggesting new methods and installing it.

Keywords - Time study, Method study, Standard time, Works Pro software, Productivity, Ergonomics

\section{INTRODUCTION}

Work study investigates the work done in an organization and aims at finding the best and the most efficient way of utilizing the available resources to achieve best possible quality of work in minimum possible time and cause least possible fatigue to the worker[1].

Work study succeeds because it is systematic both in the investigation of the problem being considered and in the development of its solution. It is only by continuous observation and study at the workplace or in the area where the activity is taking place that the facts can be obtained. The project is about to study the existing method of different work stations and suggesting improved method for the same so as to reduce the cycle time and to improve productivity. The importance of this project work is directly related to the reduction of the inefficient time and increasing the productivity.

\subsection{Problem Statement}

To study the existing method involved in assembly work station and suggesting new improved methods using work study techniques to reduce the cycle time and improve productivity.

\subsection{Research Objective}

To reduce unwanted motion involved in the operation by memo motion study of the operation involved at the assembly station and to reduce the ineffective time associated with the operation. To propose a new method of performing the job and comparing it with the existing method.

\section{LITERATURE REVIEW}

Work study is a generic term for techniques, particularly method study and work measurement[1], which are used for the examination of human work in all its contexts, and which lead systematically to investigation of all the factors which affect the efficiency and economy of the situation being reviewed, in order to seek improvements. Work study investigates the work done in an organization and aims at finding the best and the most efficient way of utilizing the available resources (man, material, money and machinery) to achieve best possible quality work in minimum possible time and causes least possible fatigue to the worker. Method study is the systematic recording and critical examination of ways of doing things in order to make improvements[2]. Work measurement is the application of techniques designed to establish the time for a qualified worker to carry out a task at a defined rate of working. Organization can maximize production and optimize costs. When this can be applied, organizations can leverage the cost and time in efforts to develop and promote them[3]. Bhasin \& Burcher [4] remark that Lean is not only tools and techniques, but it should be viewed as a philosophy. It is a 'way of thinking' After everyone was educated on $5 \mathrm{~S}$, company is walking on the road to lean. The company is running each step of $5 \mathrm{~S}$ in order to help the organization to have a better working environment and improve the process flow [5]. Workstations for assembly tasks should be designed so that any operator can adjust to his/her comfort to relieve stress and improve performance. The ergonomically designed smart assembly workstation is a solution to ergonomic and productivity problems in the workplace[6]. 


\section{ERGONOMICS}

Ergonomics composed of two Greek words i e ergos (work) and nomos (law) given a group of scientists in 1949.It also known as" human engineering". It is commonly defined as the scientific study of relationship b/w man, machine (with which he works) and environment (in which he works).Today, however, the word is used to describe the science of "designing the job to fit the worker, not forcing the worker to fit the job." Ergonomics covers all aspects of a job, from the physical stresses it places on joints, muscles, nerves, tendons, bones and the like, to environmental factors which can effect hearing, vision, and general comfort and health. It evaluates the combined effect of all these interacting factors on productivity .successful application of such tools and techniques of the domain of ergonomics may lead to the development of the most comfortable working conditions in terms of illumination, climatic condition, noise level which ensures the minimization of physical work load, to improve work posture as well to reduce the effort of certain movements.

\subsection{Rapid Upper Limb Assessment (RULA)}

Rapid Upper Limb Assessment (RULA) RULA was developed to evaluate the exposure of individual workers to ergonomic risk factors associated with upper extremity MSD. The RULA ergonomic assessment tool considers biomechanical and postural load requirements of job tasks demands on the neck, trunk and upper extremities. A single page worksheet is used to evaluate required body posture, force, and repetition. Based on the evaluations, scores are entered for each body region in section $\mathrm{A}$ for the arm and wrist, and section B for the neck and trunk.

Table 1: RULA action level

\begin{tabular}{|l|l|l|}
\hline Scores & \begin{tabular}{l} 
Requirements for Action(Level of MSD \\
\hline 1 or 2
\end{tabular} & $\begin{array}{l}\text { Indicates that posture is acceptable if it is not } \\
\text { maintained or repeated for long periods. }\end{array}$ \\
\hline 3 or 4 & $\begin{array}{l}\text { Indicates that further investigation is needed } \\
\text { and changes may be required. }\end{array}$ \\
\hline 5 or 6 & $\begin{array}{l}\text { Indicates investigation and changes are } \\
\text { required soon. }\end{array}$ \\
\hline 7 & $\begin{array}{l}\text { Indicates investigation and changes are } \\
\text { required immediately }\end{array}$ \\
\hline
\end{tabular}

\subsection{Rapid Entire Body Assessment (REBA)}

Rapid Entire Body Assessment (REBA) This ergonomic assessment tool uses a systematic process to evaluate whole body postural MSD and risks associated with job tasks. A single page worksheet is used to evaluate required or selected body posture, forceful exertions, type of movement or action, repetition, and coupling. Rapid Entire Body Assessment (REBA) Using the REBA worksheet, the evaluator will assign a score for each of the following body regions: wrists, forearms, elbows, shoulders, neck, trunk, back, legs and knees.
Table 2 REBA action level

\begin{tabular}{|l|l|}
\hline SCORE & Level of MSD Risk \\
\hline 1 & Negligible risk, no action required \\
\hline $2-3$ & Change may be needed \\
\hline $4-7$ & Medium risk, further investigation \\
\hline $8-10$ & Highly risk, investigate ,implement change \\
\hline $11+$ & Very high risk implement change \\
\hline
\end{tabular}

\section{RESEARCH METHODOLOGY}

This chapter will discuss methods used in research studies to obtain results. The data obtained will be collected and analyzed according to the proper specifications and appropriate. Among the important aspects to be considered here is the framework of research, study design, data collection methods, research instruments and measurement tools for analyzing research data.[3].

\subsection{Data Collection}

Data and information collected is shaped primary data and secondary data. Primary data refers to data taken from the results of the observations made in the study done.

While secondary data were obtained through reading printed materials such as research journals, reference books related to research this subject, all previous research findings and articles needed to ensure the accuracy of the information, to enhance interpretation and understanding, and to produce high quality research. Information from Internet sources are also utilized in the best possible in the conduct of this study [3].

\subsection{Work Pro Software}

Work Pro is the software for doing Improvements in your organization though the use of Video Work Study (VWS).Work Pro is the software for doing improvements in your organization through Video Work Study (VWS). Video Work Study is the most economical, effective and a fast way to improve your operations and hence the profitability. The main objective of the software is to make improvements a simple \& natural way of life for all in organizations.

\subsection{Observation}

In this study, conducted systematic observations of researchers required to observe overall work process in the factory, then the selection was made and carried out research work and the only process that only want to review. Based on observation, it is necessary to record everything that happens in every process from start until end of work processes [3].

\subsection{Video Work Study}

Video Work Study is doing the study of any work with the help of videos and with suitable software for capturing \& recording the Work Study data. All the calculations, analysis etc are doing using the software. Video Work Study gives a recorded knowledge of the work being studied. This recorded knowledge is stored in a simple format understandable \& usable. 


\subsection{Comparison between VWS \& Manual Time}

\section{Studies}

Manual Work Study is done using a stopwatch plus a writing pad and mainly done on paper. The very purpose of even this Study is for doing improvements to the work. Manual Study results are reported in a book form - mostly kept with the top management \& Industrial Engineering department or personnel department. The basic principles of VWS are the same as that of manual studies but VWS simplifies the usage and application of these principles as it uses Video and a database. The use of Video technology makes it also verifiable. It will also find that the any work video can be seen repeatedly, compared activity by activity between operators / machines / tooling / plants /companies VWS is also more productive than manual stopwatch studies and is quite accurate in time data as well as analysis data. Hence, the productivity of the Industrial Engineer or the person doing such studies is also increased in the first place as many of the study tasks like time calculations, analysis etc are performed by using works pro software.

\subsection{Data Analyze}

After data collection is carried out, the next step is to analyze the data carefully for this we need to insert the video in works pro software and video is made to run so that disintegrate the video in process, operations and activities. Experiments carried out on all the facts and the data were recorded using charts and graphs which are produced using Works Pro software.

\section{DATA ANALYSIS AND OUTCOME}

In completing this research and to achieve each objective, it is important to analyze the data. The main thing that is focused in this chapter is to identify the result of research findings researchers to achieve the objectives of the study conducted. In Manual work study data is collected using stop watch flow process chart is prepared and in Video work study the video is disintegrated and standard time, Flow process chart, R?V?N charts are generated using works pro software.

\subsection{Comparison Manual Work Study of Existing}

\section{Method \&Proposed Method}

Table 3 comparison manual work study of existing \&proposed method

\begin{tabular}{|l|c|c|c|}
\hline \multicolumn{1}{|c|}{ ACTIVITY } & $\begin{array}{c}\text { PRESEN } \\
\text { T (SEC) }\end{array}$ & $\begin{array}{c}\text { PROPOSE } \\
\text { D (SEC) }\end{array}$ & $\begin{array}{c}\text { SAVING } \\
\text { S (SEC) }\end{array}$ \\
\hline OPERATIONS & 1522 & 1137 & 385 \\
\hline INSPECTION & 112 & 96 & 16 \\
\hline $\begin{array}{l}\text { TRANSPORTATI } \\
\text { ON }\end{array}$ & 521 & 396 & 125 \\
\hline DELAY & 462 & 35 & 427 \\
\hline STORAGE & & 120 & -51 \\
\hline $\begin{array}{l}\text { COMBINED } \\
\text { ACTIVITY }\end{array}$ & 2686 & 1784 & 902 \\
\hline TOTAL & & & \\
\hline
\end{tabular}

Table 3 above shows the comparison between the manual work study of existing and proposed method. In Existing Method there was a lot of time spent on Transportation and Delay because of improper work layout .Transportation takes 521 seconds and Delay takes 362 seconds in which a lot of non value activities found. In Proposed method by changing the work layout most of non value added activities have been eliminated. In proposed method Transportation takes 521 seconds and Delay takes 35 seconds. So by doing this a lot of time is saved and the time required to complete the assembly is reduced.

\subsection{Video Work Study of Existing Method}

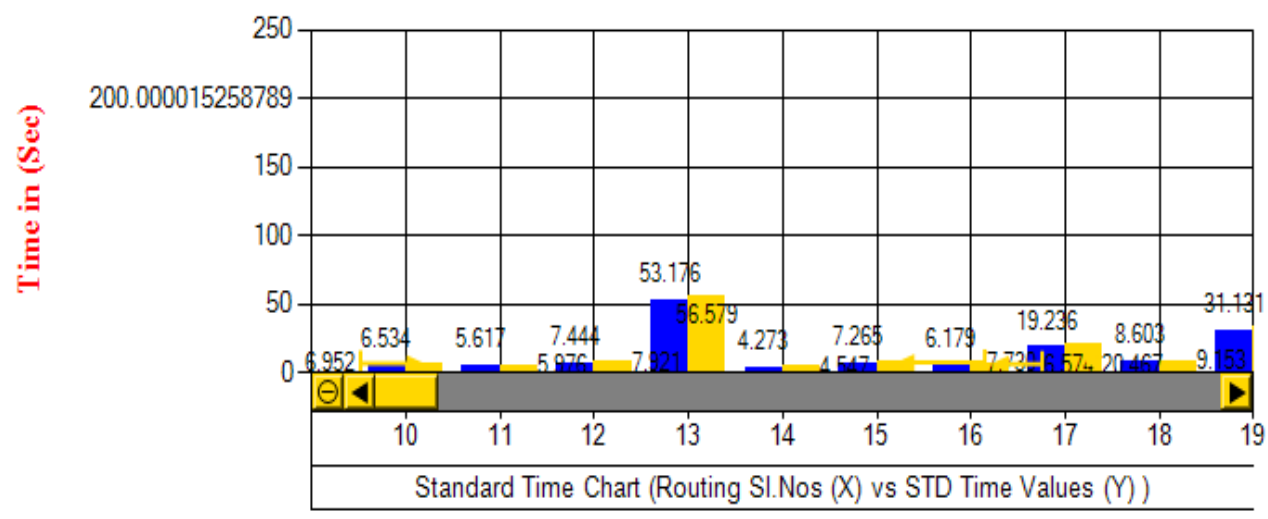

Figure 1 Standard Time And Flow Analysis Chart 
Based on the histogram in Figure 1 above, we can know that the standard time required to complete various activities in existing method. .

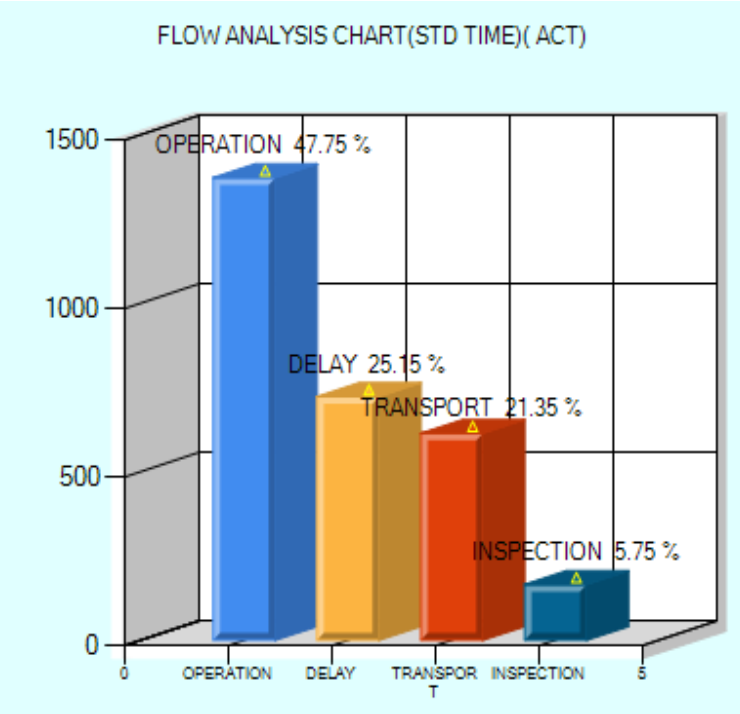

Fig 2 Flow Analysis Chart

Based on the histogram in Figure 2 above, we can see in a process Transportation takes $\mathbf{2 1 . 3 5 \%}$ and Delay takes $\mathbf{2 5 . 1 5 \%}$ because of improper work layout

\section{VAINVA/RNVA VALUE ANALYSIS CHART (STD TIME)( ACT)}

\begin{tabular}{ccc} 
TYPE & TOTAL & $\%$ \\
\hline N & 777.474 & $27.05 \%$ \\
R & 831.755 & $28.94 \%$ \\
V & 1.265 .056 & $44.01 \%$
\end{tabular}

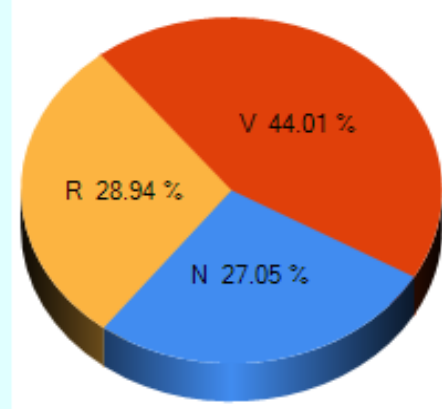

Fig 3 R/V/ N Chart

Figure 3 shows $\mathrm{R} / \mathrm{V} / \mathrm{N}$ chart which shows in a process $\mathbf{2 7 . 0 5 \%}$ of Non value added activities are involved and required value added takes $\mathbf{2 8 . 9 4 \%}$, Value added activities involved is $\mathbf{4 4 . 0 1 \%}$.

\subsection{Video Work Study of Proposed Method}



Fig 4 Standard Time And Flow Analysis Chart

Based on the histogram in Figure 4 , we can know that the standard time required completing various activities in proposed method. 


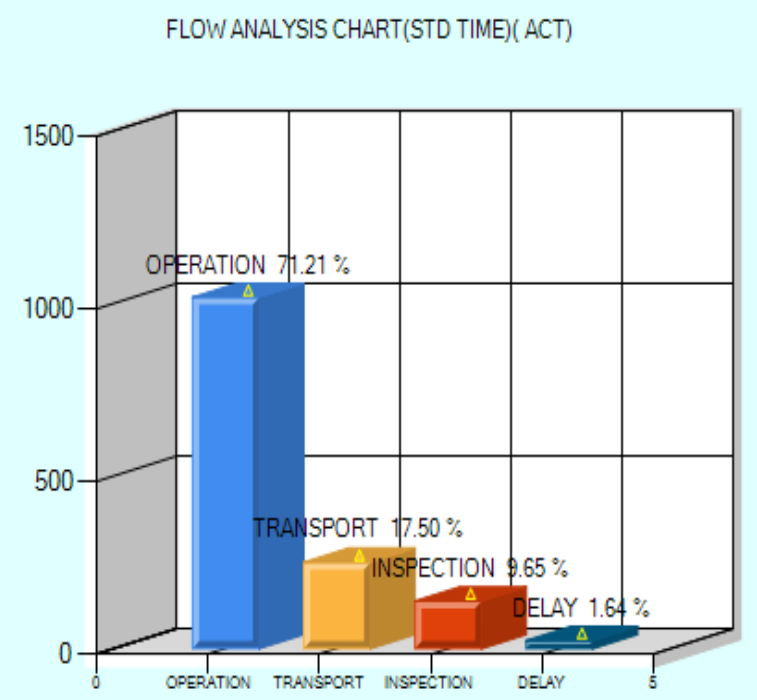

Fig 5 Flow Analysis Chart

Table 4: comparison manual work study of existing \&proposed method

\begin{tabular}{|l|l|l|l|}
\hline & $\begin{array}{l}\text { EXISTNG } \\
\text { METHOD } \\
\text { (SEC) }\end{array}$ & $\begin{array}{l}\text { PROPOSED } \\
\text { METHOD } \\
\text { (SEC) }\end{array}$ & $\begin{array}{l}\text { TIME } \\
\text { SAVED } \\
\text { (SEC) }\end{array}$ \\
\hline $\begin{array}{l}\text { MANUAL } \\
\text { WORK } \\
\text { STUDY }\end{array}$ & 2685.6 & 1784 & 901 \\
\hline $\begin{array}{l}\text { VIDEO } \\
\text { WORK } \\
\text { STUDY }\end{array}$ & 2729.5 & 1856 & 873.5 \\
\hline
\end{tabular}

Based on the histogram in Figure 5 above, we can see in a process Transportation takes $\mathbf{1 7 . 5 7 \%}$ and Delay takes $\mathbf{1 . 6 4 \%}$ because of after changing work layout work layout.
VAINVA/RNVA VALUE ANALYSIS CHART (STD TIME)( ACT)



Fig 6 R/V/ N Chart

Figure 6 shows chart which shows in a process $\mathbf{0 . 7 6 \%}$ of Non value added activities are involved and required value added takes $\mathbf{2 9 . 1 6 \%}$, Value added activities takes $\mathbf{7 0 . 0 8 \%}$.

\subsection{Comparison of Existing and Proposed Method}

The time taken for assembly is taken by the video work study analysis as it is more precise than the manual recording technique. Hence for further calculations the time taken in the video study is considered.

Existing method $\mathbf{= 4 5 . 4 9}$ minutes

Proposed method $=\mathbf{3 0 . 9 4}$ minutes

Savings $=\mathbf{1 4 . 5 5}$ minutes

\subsection{Comparison of RULA \& REBA Existing and Proposed Method}

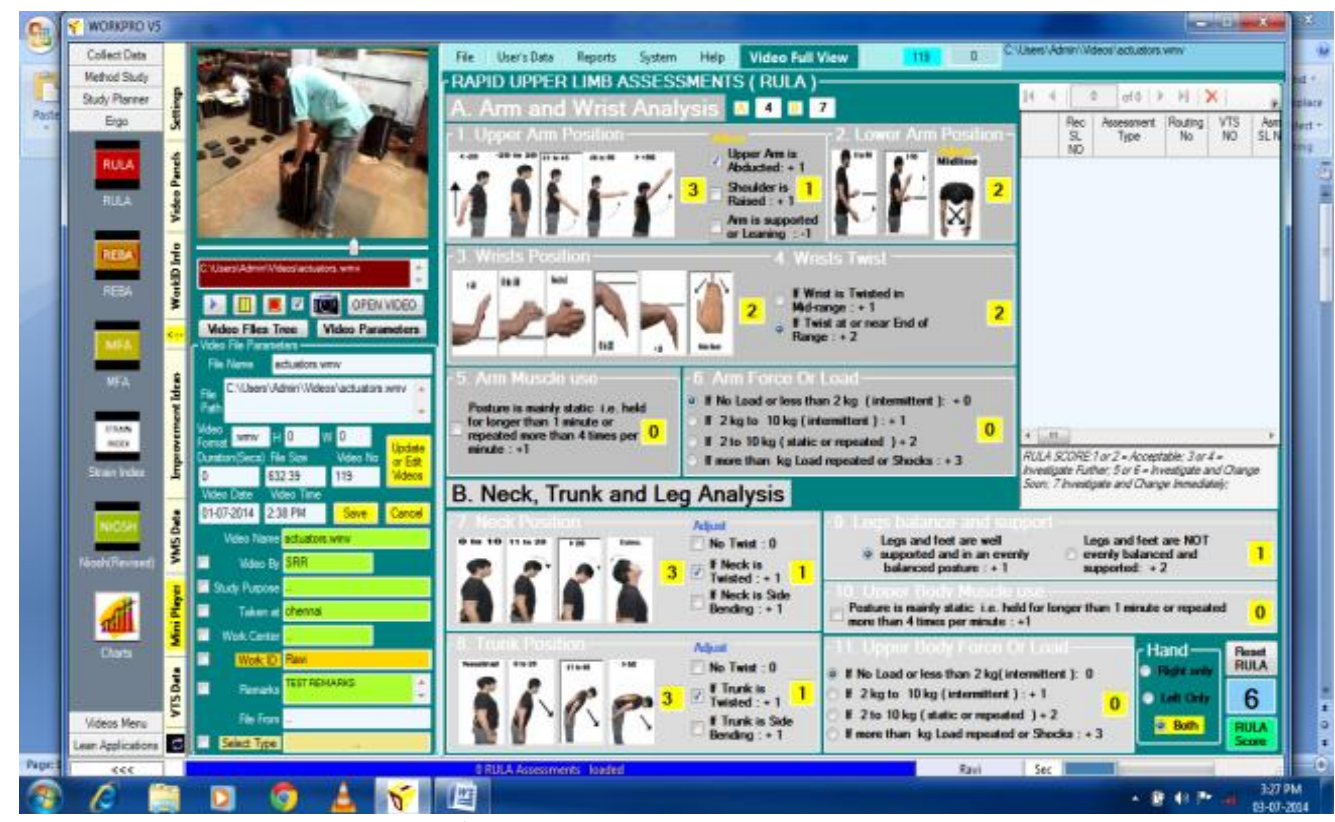

Fig 7 RULA Of Existing Method 


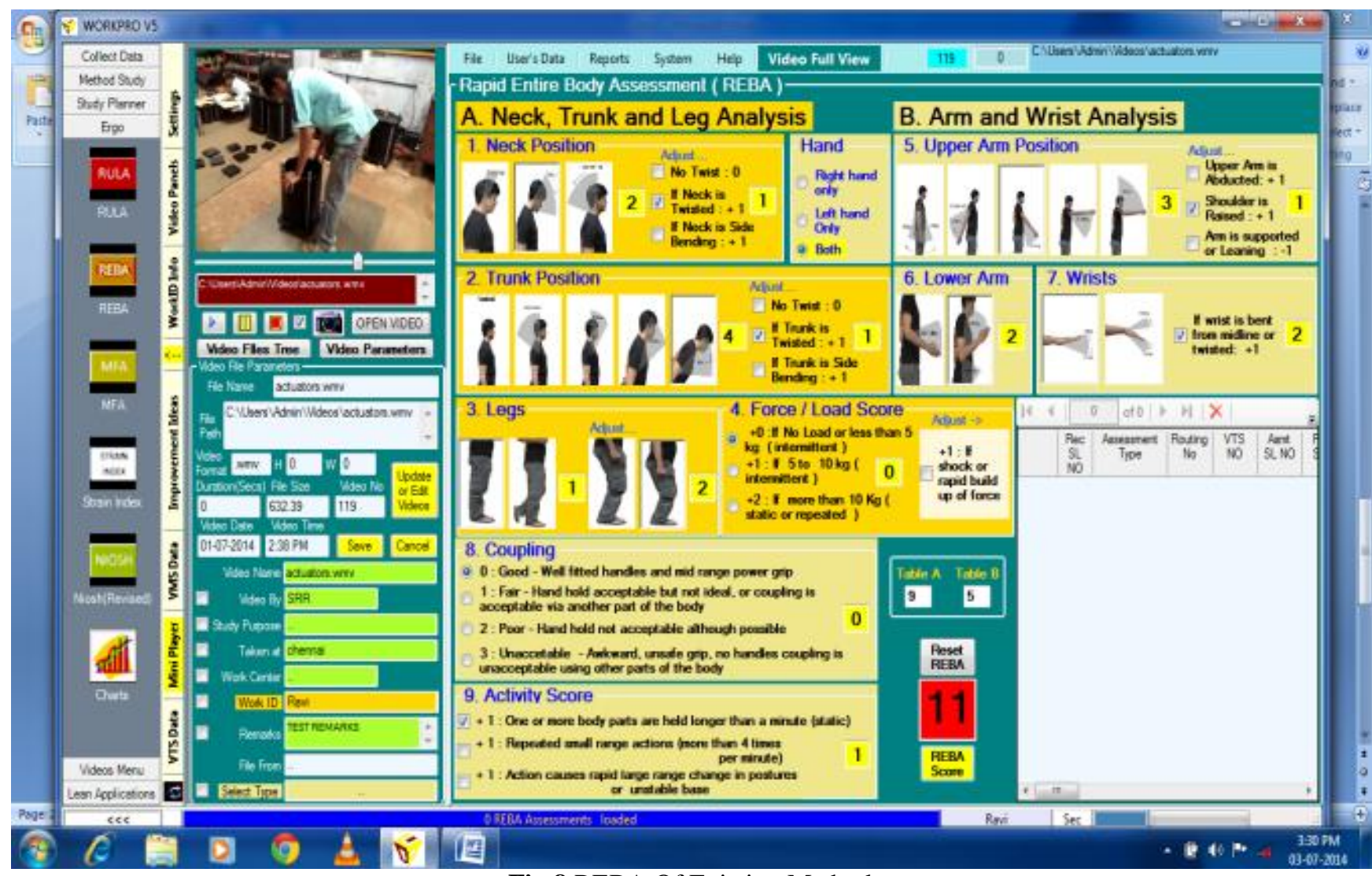

Fig 8 REBA Of Existing Method

In figure 7 It is observed that RULA score was found as 6 which indicates that changes are required soon. In figure $8 \mathrm{It}$ is observed that REBA score was 11 which indicates very high risk and implement the change.

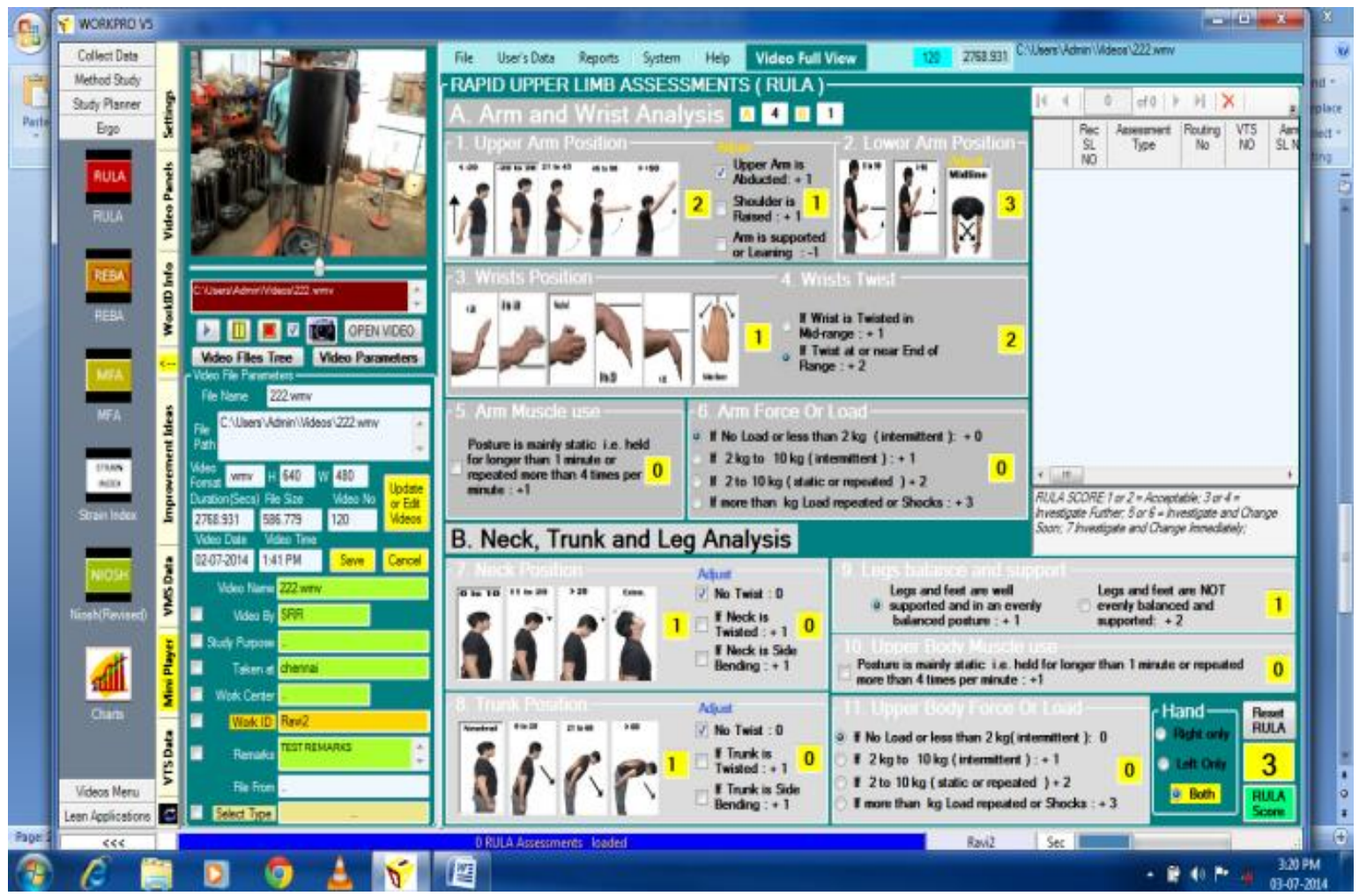

Fig 9 RULA Of Proposed Method 


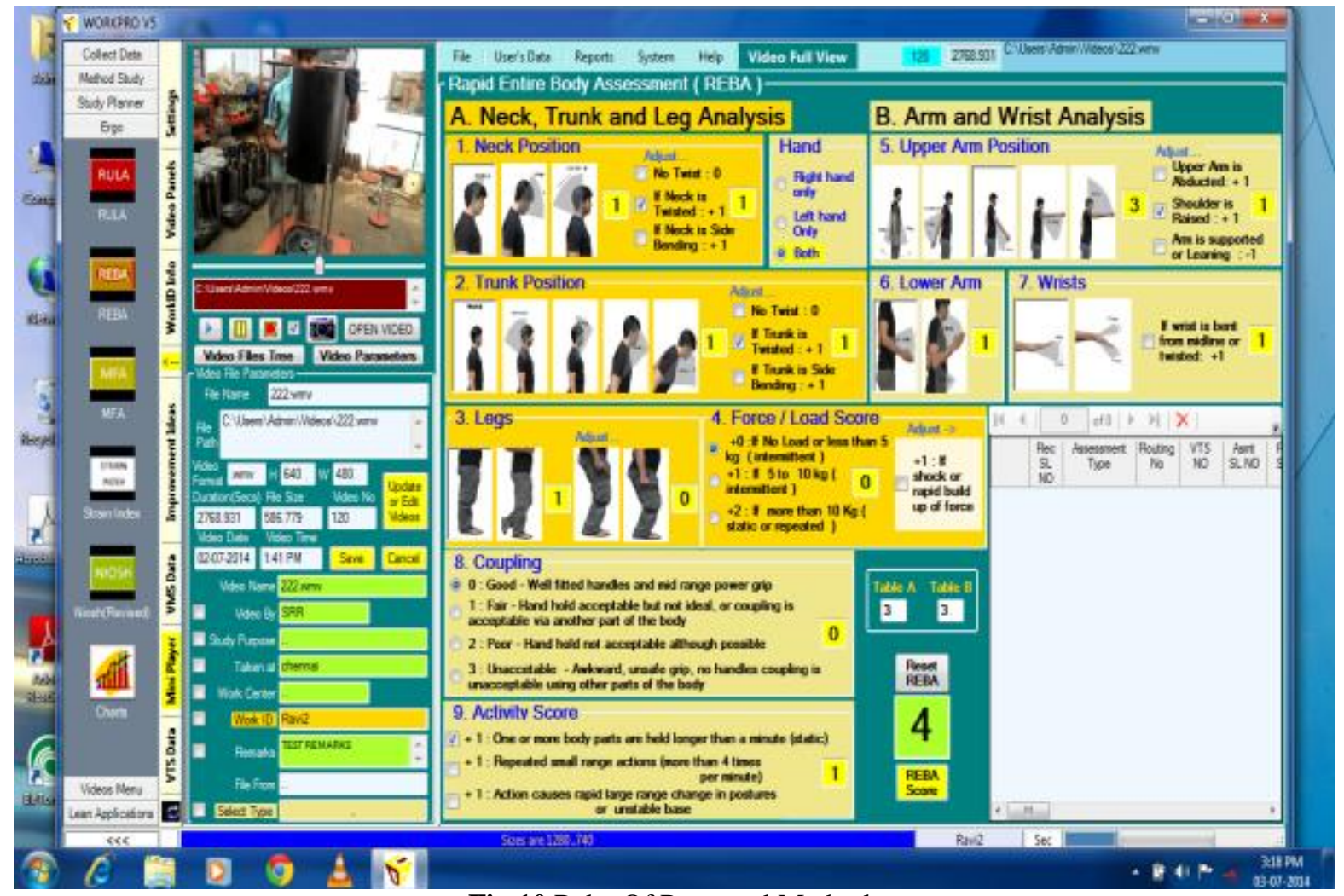

Fig 10 Reba Of Proposed Method

In figure 9 It is observed that RULA score was found as 3 which Indicates that further investigation is needed and changes may be required. In figure $10 \mathrm{It}$ is observed that REBA score was 4 which indicates medium risk and investigate.

\section{RESULTS AND DISCUSSIONS}

\subsection{Productivity Improvement}

By present method

1. Working hour of one operator $=8$ hours $=\mathbf{4 8 0}$ minutes

2. Present productivity For one model of 10 inch actuator it takes $\mathbf{4 5 m i n u t e s}$

3. In a day he assembles $\mathbf{1 0}$ actuators

Existing productivity of 10 inch actuator is

2 workers $* 10$ actuator $\mathrm{s}=20$ actuators

By Proposed method

1. For one model of 10 inch actuator it takes $=\mathbf{3 1}$ minutes

2. In a day he can assemble $=\mathbf{1 5}$ actuators

3. Hence there is productivity improvement from 15 actuators per day per workers to 10 actuators per day per worker.

So productivity improvement per day at assembly section for 10 inch actuator is 2 workers $* 15$ actuators $=30$ actuators.
Existing productivity (per worker per day)

$10 * 2=20$ actuators per day

\section{Improved productivity}

$15 * 2=30$ actuators per day

The company has to bare the following cost for the implementation of new method

1. Assembly table is 5000/-

2. Fastener tray is 450 /-

3. Total $=5450$ rupees per assembly table

4. Number of workers per station $=1$ (two tables per station)

5. Therefore $5450 * 1=5450 /$ - per station

6. Number of stations is $2 * 5450=10900 /-$ for the whole assembly section (one time investment)

\subsection{Breakeven Point}

1. The profit for one model of 10 inch actuator is rupees 570/-

2. Per day productvity improvement is 30 actuators

3. So total profit per day for the improved productivity is $30 * 570=17100 /-$

4. The break even point is achieved in a three days if the proposed method is followed.

Per day productivity improvement

Number of workers at the assembly section is $=2$ 
So productivity improvement per day at assembly section for 10 inch actuator is 2 workers $* 5$ alternators $=10$ actuators per day at assembly section.

\section{CONCLUSIONS}

The unwanted motion involved in the operation of assembly has been substantially reduced by designing assembly table, fasteners tray and design of proper work place layout.Proper method has been given to the operators to get the materials from the store house.Naming of the work place layout has been done, so that materials are placed at proper place.

The ineffective time associated with the assembly operation has been reduced by Suggesting a proper sequence of operations which reduces the time of assembly of 10 inch actuator.The existing method takes a time of $\mathbf{4 5 . 4 9}$ minutes for the assembly of the alternator.The proposed method of assembly 10 inch actuator takes a time of $\mathbf{3 0 . 9 4}$ minutes.For one assembly of 10 inch actuator the operator saves a time $\mathbf{1 4 . 5 5}$ minutes.

\section{REFFERENCES}

[1]. Introduction to work study, International Labour Office, Geneva, International Labour Organisation fourth edition 1992.

[2] Suresh Dalela, A text book of Work Study, Standard publishers, third edition, 1983

[3]. Abdul Talib Bon, Daiyanni Daim(2010). "Time Motion Study in Determination of Time Standard in Manpower Process." 3rd Engineering Conference on Advancement in Mechanical and Manufacturing for Sustainable Environment.

[4]. Bhasin, S. \& Burcher, P (2006). Lean viewed as a philosophy. Journal of Manufacturing Technology Management

[5]. HungLin, Chi (May, 2011) 5S Implementation in Wan Cheng Industry Manufacturing Factory in Taiwan.

[6]. Ibrahim H. Garbie. " An Experimental Study On Assembly Work Station Considering Ergonomically Issues."

[7]. Er. Rajesh Kumar Mehta (et al 2012) An Exploratory Study on Implementation of Lean Manufacturing Practices (With Special Reference to Automobile Sector Industry)

[8]. Wiesław Grzybowski (2001) "Time Motion Study in Determination of Time Standard in Manpower Process." International Journal of Occupational Safety \& Ergonomics 2001, VOL. 7, NO. 2, 223-237. 